\title{
Direct and Indirect Harassment Experiences and Burnout among Academic Faculty in Japan
}

\author{
Masumi Takeuchi, ${ }^{1,2}$ Kyoko Nomura, ${ }^{3,4}$ Saki Horie, ${ }^{5}$ Hiroko Okinaga, ${ }^{6}$ \\ Chithra R. Perumalswami ${ }^{7}$ and Reshma Jagsi ${ }^{7,8}$

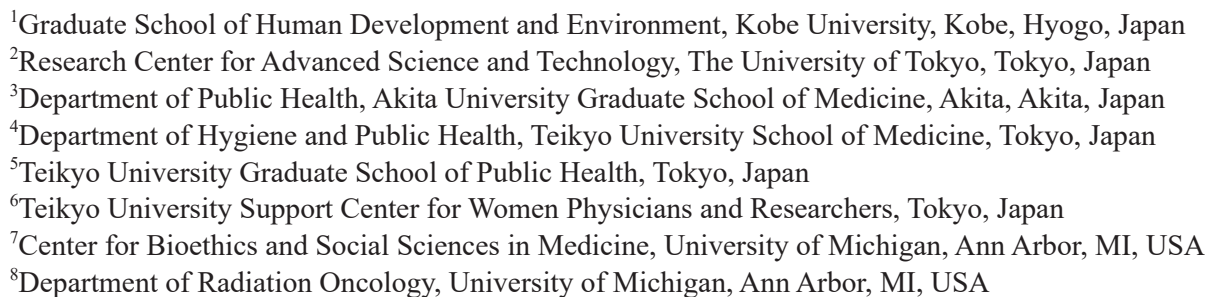

The purpose of this study is three-fold: (1) to compare harassment (sexual, gender, and academic harassment both directly and indirectly experienced - i.e. "directly harassed" and "have seen or heard of someone who experienced harassment", respectively) experienced by males and females, (2) to investigate whether such experiences correlate with burnout, and (3) to explore whether social support might mitigate any such relationship between harassment and burnout. This cross-sectional study was conducted at a private university in Japan in February 2014 and is based on a work-life balance survey obtained from 330 academic faculty members. We investigated the association between each of the six subcategories of harassment (direct and indirect forms of each of the three types) and burnout using general linear regression models; we then evaluated interactions between harassment and social support in these models. The prevalence of direct and indirect experiences of harassment was higher in females than in males for all three types of harassment. Males showed higher burnout scores if they had direct experiences of harassment. There were significant interactions between social support and the direct experience of harassment; high social support mitigated the effect size of direct harassment on burnout among males. Females showed higher burnout scores if they had indirect experiences of harassment. However, the same buffering effect of social support on burnout as observed in males was not observed in females. Direct harassment experiences increased the risk of burnout in males, and indirect harassment experiences increased burnout in females.

Keywords: academic faculties; burnout; gender; harassment; social support

Tohoku J. Exp. Med., 2018 May, 245 (1), 37-44. C 2018 Tohoku University Medical Press

\section{Introduction}

As noted recently in Nature, early-career researchers are being squeezed out of Japanese universities (Fuyuno 2017). The number of papers published by Japanese universities, organizations, and companies decreased $4.3 \%$ between 2006 and 2010, whereas UK universities' publications increased $12.7 \%$ and Germany's gained $15 \%$ over the same time period (Fuyuno 2012). The condition appears more serious among females. The number of faculty members leaving their jobs is higher among females $(6.6 \%)$ than males (4.4\%) in Japan (Kato et al. 2012). The population of female researchers in Japan was only $14.4 \%$ in 2013, strikingly low in comparison to other nations, such as
Russia (41.2\%), the United Kingdom (37.7\%), or the United States (33.6 \%) (Gender Equality Bureau Cabinet Office 2014). This finding is unlikely to be explained exclusively by demographic changes, such as decreasing birthrate and aging of the population. It is likely explained also by the gendered division of labor embedded in Japanese culture, as well as the permeation of gender biases into the working environment surrounding early-career researchers. Of particular concern is the potentially insufficient role of mentoring and the lack of social support within the Japanese university culture and the increased possibility of burnout and psychological distress due to harassment.

We chose to focus on describing the prevalence of harassment experienced both directly and indirectly by

Received February 13, 2018; revised and accepted April 25, 2018. Published online May 12, 2018; doi: 10.1620/tjem.245.37.

Correspondence: Kyoko Nomura, M.D., M.P.H., Ph.D., Department of Public Health, Akita University Graduate School of Medicine,

1-1-1 Hondo, Akita, Akita 010-8543, Japan.

e-mail: nomurakyoko@gmail.com 
male and female university faculty in Japan because harassment is known to decrease the motivation of workers through psychological distress. Such distress often results in early retirement (Fitzgerald et al. 1997; Lapierre et al. 2005). Workplace harassment has been defined as a situation where a person is subjected to negative acts on the job (Andersen et al. 2010); harassment may be sexual or gender-related, but this is not the only form of harassment. Previous studies have shown that faculty members in educational settings including universities are at risk of becoming victims of work harassment by their colleagues and superiors (Astrauskaite et al. 2010), potentially because of a perceived imbalance in power whereby the victim finds it difficult to defend him or herself.

Moreover, previous studies have also demonstrated that harassment can have negative job-related, psychological, and health outcomes not only on direct victims, but also on witnesses or bystanders (Glomb et al. 1997; Vartia 2001). It can adversely affect team relationships and team performance as well (Raver and Gelfand 2005). Employees who experience sexual harassment, or whose workplace is subject to sexual harassment, often report higher levels of absenteeism and intentions to quit and are more likely to leave work (Glomb et al. 1997). Thus, harassment appears to be a social problem with potentially widespread influence beyond the individual victim. Previously, very few studies have focused on "indirect" experiences of harassment, and this problem is often ignored in society. In this study, we defined "direct harassment" as an experience of direct harassment and victimization and "indirect harassment" as the experience of witnessing or hearing someone being directly harassed.

Given the limited understanding of the prevalence of harassment within Japanese university settings and ongoing concerns about the retention of faculty and their productivity in this setting, we conducted a study to investigate these experiences among males and females at a single university, to evaluate if direct and/or indirect experiences of harassment were associated with burnout, and to explore whether social support within the workplace mitigates any such harassment-related psychological distress.

\section{Methods}

\section{Participants}

This cross-sectional study was conducted between February and March 2014 at a private university in Japan. The university has five campuses that include schools of Medicine, Pharma-Science, Medical Technology, Science and Engineering, Economics, Law, Liberal Arts, Language, and Education. Each school has many academic faculty members. Japanese females face challenges of balancing work and private lives, which often results in early retirement at the time of child-bearing. This university actively promotes gender equity in academia; the proportion of females among the faculty at this university is $20.2 \%$, which is much higher than other universities in Japan $(14.4 \%)$. Such a unique setting enabled us to include questions about harassment, especially sexual harassment, that otherwise might have been considered too difficult or taboo to ask. We sent a self-administered questionnaire about work environment, including measures of direct and indirect harassment experience, burnout, and social support in addition to baseline sociodemographic characteristics. We surveyed all 1,189 faculty members who were registered as full-time employees, and among these, 330 faculty members anonymously submitted responses (response rate 27.8\%).

All participants provided written informed consent and were blinded to the research hypotheses. All procedures were approved by the Institutional Review Board of Teikyo University School of Medicine (number 15-141).

\section{Measures}

Harassment: The key independent variables of interest in our analyses were measures of harassment. Using previously validated measures, we measured both direct and indirect experiences of three types of harassment: sexual, gender, and academic. Direct harassment was defined as a respondent directly experiencing harassment; indirect harassment was defined as a respondent who did not experience direct harassment but had seen or heard of someone else who experienced direct harassment. Participants were asked to report any direct or indirect ("seen and/or heard") experiences in a university setting or associated settings, such as research seminars or workrelated social gatherings. A subject was considered to have had a "harassment experience" if a respondent answered that he or she had experienced at least one behavior in each category.

Sexual harassment and Gender harassment: Experience of sexual harassment was assessed according to 20 behaviors in the workplace used in the previous study of Sano and Munakata (1999), which was revised to suit the Japanese workplace from the Sexual Experiences Questionnaire (SEQ) originally developed by Fitzgerald et al. (1995). In this present study, we further categorized the 20 behaviors into two types of sex-related behaviors based on previous studies: "sexual harassment" in a narrow sense (11 behaviors) and "gender harassment" (9 behaviors) (Fitzgerald et al. 1995; Sano and Munekata 1999). "Gender harassment" was defined as discriminatory, degrading, and imposing gender roles, whereas "Sexual harassment" was defined as remarks and behaviors with regards to unwanted sexual attention and solicitation (Parker and Griffin 2002). In this way, it differed from the definition of gender discrimination and sexual harassment as per the Till spectrum, which defines severity of harassment as specific characteristics (Till 1980). The details of these behaviors are described in appendix.

Academic harassment: Non-sexual harassment in a university setting is termed "academic harassment" in Japan (Ogoshi and Akamatsu 2005; Ogoshi 2009). This form of harassment has been defined as "bullying" related to research or other activities within the academic setting. Our measures of the experience of academic harassment were based on 19 behaviors used in a previous survey by Ogoshi and Akamatsu (2005); the details of these measures are translated in the appendix. Examples include: "Have you ever been banned from attending a seminar or conference?", "Have you ever been removed from coauthor lists of scientific papers?", and "Have you ever been abused verbally by your boss?"

Outcome measurement, burnout: The burnout scale used in this present study was developed by Japanese researchers, Tao and Kubo 
(1992), who developed this measure from the Maslach Burnout Inventory (MBI) (Maslach and Jackson 1981). This scale includes 17 items measuring emotional exhaustion, depersonalization, and feelings of reduced personal accomplishment. This scale is a standardized assessment of burnout in workers who provide human service to others, like academics, teachers and healthcare workers. Each item was measured based on a frequency of their experience in previous 6 months by using a 5-point Likert-scale range from "never" to "always". The burnout score was an average of 17 items with a range of 1-5 points. According to one study reported by Tao (1989), who invented the score, the average score was 2.38 in a sample of nurses, physical therapists, operational therapists, and home helpers.

Social support: We measured social support within the workplace using a scale developed by Komaki and Tanaka (1993), which was originally derived from several other instruments, including the Social Support Questionnaire (Sarason et al. 1983), Interpersonal Support Evaluation List (Cohen, et al. 1985), and Inventory of Socially Supportive Behaviors (Barrera et al. 1981). This scale includes 15 items that measure to what extent a boss or a colleague in the workplace would provide supportive behaviors and communication. The response pattern is based on a 5-point Likert-scale ranging from "applies" to "does not apply."

Covariates: In this present study, key covariates included gender, age, marital status, parental status, department, academic rank (grouped as "professor, associate professor, or lecturer" versus "assistant professor or assistant"), daily work hours, self-reported household income based on the previous fiscal year (rated with a 5-point response scale ranging " 5 . upper" "4. upper-middle" "3. middle" "2. lower-middle" "1. lower"), and self-reported health status (rated with a 5-point response scale ranging "5. very healthy" "4. healthy" "3. middle" "2. not so healthy" "1. not healthy"). Department was categorized into two groups of "medical and natural science" versus "social science and art". The "medical and natural science" category included faculties of medicine, science and engineering, pharma-science, and medical technology, while "social science and art" included faculties of liberal arts, economics, law, language, and education.

\section{Statistical analysis}

First, gender differences in harassment experiences were assessed by a chi-square test. In order to investigate an effect of direct and indirect harassment experience on burnout, general linear regression analyses were used, and the standard partial regression coefficient $b$ were examined; the value of $b$ indicates how much units the dependent variable increases (or decreases) with a one-unit increase of a linear independent variable or with the presence of a categorical independent variable. Multivariable analyses were conducted separately among male and female respondents after adjusting for age, marital status, children, self-reported health status, selfreported household income, department, position, and working hours per day. Model 1 assessed a relationship between each of the six measures of harassment on burnout, after adjustment for all covariates. Model 2 then introduced as an additional independent variable: social support, evaluating both direct associations and interactions with each of the six measures of harassment on burnout. Significance level was set at $p<.05$. All analyses were conducted using IBM SPSS Statistics Version 20 (IBM Corp., Armonk, NY, USA).

\section{Result}

Table 1 indicates participants' characteristics. The percentage of females $(30.9 \%)$ and percentage of respondents serving on medical and natural science faculties (70.1\%) in our responding sample were similar to the population of the university where the present study was conducted: $20.2 \%$ of faculty members are females and $64.8 \%$ of faculty members belong to medical and natural science faculties. The structures of age (under 30s $20.1 \%$, 40s $25.5 \%$, 50s $29.5 \%$, over $60 \mathrm{~s} 24.9 \%$ ) and current position (professor, associate professor, lecturer 76.4\%) in our participants were also similar to those of our source population (under 30s $20.4 \%$, 40s $27.0 \%$, 50s $28.8 \%$, over 60 s $23.9 \%$, professor, associate professor, lecturer 69.7\%). Working hours per day were 9.65 hours, longer than the average working hours in Japan (8.4 hours; Ministry of Health, Labor and Welfare 2017). The mean burnout score was 2.29, which was not much different from the result of the study mentioned previously (Tao 1989).

Table 2 shows the prevalence of direct and indirect experiences of each type of harassment, by sex. The prevalence of direct experiences of each form of harassment among females was $10.4 \%$ for sexual harassment, $24.0 \%$ for gender harassment, and $34.0 \%$ for academic harassment, while the corresponding prevalences among men were $5.2 \%, 9.3 \%$, and $23.4 \%$, respectively. Females were significantly more likely to report direct experiences of gender

Table 1. Characteristics of participants.

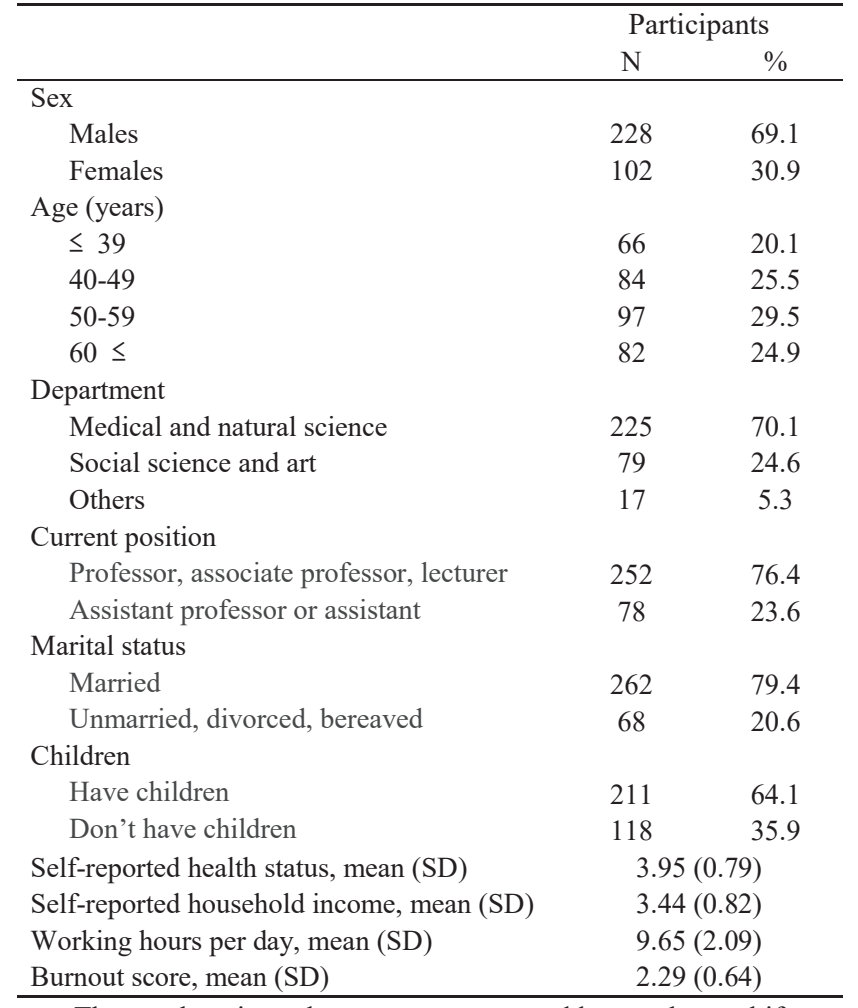

The numbers in each category may not add up to the total if the data contains missing values. 
harassment $(p=.001)$ and academic harassment $(p=.047)$, as well as indirect experiences of academic harassment $(p=$ .030 ), than men. For men, younger faculty (under 49 years old), were more likely to experience all types of harassment compared to older faculty (over 50 years old). Specifically, the percentages were as follows, respectively: $(10.0 \%$ among young men vs. $1.6 \%$ among older men, $X^{2}(1)=7.36$, $p=.010$ for sexual harassment; $18.9 \%$ among young men vs. $2.4 \%$ among older men, $\mathrm{X}^{2}(1)=16.53, p=.000$ for gender harassment; $32.3 \%$ among young men vs. $17.2 \%$ among older men, $\mathrm{X}^{2}(1)=6.80, p=.010$ for academic harassment).

The results of general linear regression models (with the outcome being burnout and independent variables of

Table 2. Sex difference of harassment experience.

\begin{tabular}{lccccc}
\hline & \multicolumn{2}{c}{ Female } & \multicolumn{2}{c}{ Male } & \multirow{2}{*}{$\mathrm{X}^{2}$} \\
& $\mathrm{~N}$ & $\%$ & $\mathrm{~N}$ & $\%$ & \\
\hline Direct harassment & & & & & \\
$\quad$ Sexual harassment & 10 & 10.4 & 11 & 5.2 & $2.88^{\dagger}$ \\
Gender harassment & 23 & 24.0 & 20 & 9.3 & $11.85^{* *}$ \\
$\quad$ Academic harassment & 34 & 34.0 & 52 & 23.4 & $3.94^{*}$ \\
Indirect harassment & & & & & \\
$\quad$ Sexual harassment & 29 & 30.2 & 43 & 20.2 & $3.72^{\dagger}$ \\
Gender harassment & 51 & 53.1 & 93 & 43.5 & 2.49 \\
Academic harassment & 63 & 63.0 & 111 & 50.0 & $4.69^{*}$ \\
\hline$* * p<.01 ; * p<.05 ;{ }^{\dagger} p<.10$. & & & &
\end{tabular}

interest being the six measures of harassment) are shown in Table 3 for males and Table 4 for females. In males, direct experience of all three types of harassment were associated with greater burnout (sexual harassment: $b=.754, p<.01$, gender harassment: $b=.360, p<.05$, academic harassment: $b=.230, p<.05)$ but indirect experience with all three types of harassment was not associated with burnout. There were significant interactions observed between social support and the direct experience of sexual harassment $(b=$ $-.403, p<.05)$ and between social support and the direct experience of gender harassment $(b=-.303, p<.05)$. The interaction between social support and the direct experience of academic harassment did not reach significance $(b=$ $-.218, p=.059)$. Fig. 1 shows simple slope analysis for the association between direct experience of harassment and burnout tested for low ( -1 SD below the mean) and high ( $+1 \mathrm{SD}$ above the mean) levels of social support. The effect size of direct harassment experience on burnout was positive (increasing burnout) and statistically significant when social support was low (sexual harassment: $b=.977, p<$ .001 , gender harassment: $b=.415, p<.01$, academic harassment: $b=.413, p<.01)$, but this relationship was not statistically significant when social support was high (sexual harassment: $b=.310$, n.s., gender harassment: $b=-.094$, n.s., academic harassment: $b=.030$, n.s. $)$.

Table 3. Effect of Three Types of Harassment on Burnout: Male.

\begin{tabular}{|c|c|c|c|c|c|c|c|}
\hline & \multirow{3}{*}{$\begin{array}{c}\text { Crude } \\
\quad r\end{array}$} & \multicolumn{6}{|l|}{ Adjustment } \\
\hline & & \multicolumn{2}{|c|}{ Sexual harassment } & \multicolumn{2}{|c|}{ Gender harassment } & \multicolumn{2}{|c|}{ Academic harassment } \\
\hline & & Model1: $b$ & Model2: $b$ & Model1: $b$ & Model2: $b$ & Model1: $b$ & Model2: $b$ \\
\hline \multicolumn{8}{|l|}{ Sexual harassment } \\
\hline Direct Sexual harassment & $.317^{* * *}$ & $.754^{* * *}$ & $.664^{* * *}$ & - & - & - & - \\
\hline Indirect Sexual harassment & .070 & -.023 & -.050 & - & - & - & - \\
\hline \multicolumn{8}{|l|}{ Gender harassment } \\
\hline Direct Gender harassment & $.293^{* * *}$ & - & - & $.360^{*}$ & .149 & - & - \\
\hline Indirect Gender harassment & $.167^{*}$ & - & - & .083 & .061 & - & - \\
\hline \multicolumn{8}{|l|}{ Academic harassment } \\
\hline Direct Academic harassment & $.332^{* * *}$ & - & - & - & - & $.230^{*}$ & $.187^{\dagger}$ \\
\hline Indirect Academic harassment & $.262^{* * *}$ & - & - & - & - & $.144^{\dagger}$ & .104 \\
\hline Age & $-.220^{* *}$ & -.035 & $-.046^{*}$ & -.026 & -.038 & -.035 & $-.047^{*}$ \\
\hline Marital status $(1=$ married, $0=$ not married $)$ & $.173^{* *}$ & -.057 & -.208 & -.010 & -.131 & -.009 & -.127 \\
\hline Children $(1=$ have children, $0=$ don't have $)$ & $-.125^{\dagger}$ & -.108 & -.091 & -.092 & -.071 & -.118 & -.113 \\
\hline Self-reported health status & $-.297^{* * *}$ & $-.251^{* * *}$ & $-.191^{* * *}$ & $-.245^{* * *}$ & $-.188^{* *}$ & $-.214^{* * *}$ & $-.160^{* *}$ \\
\hline Self-reported household income & $-.239^{* * *}$ & $-.109^{*}$ & -.082 & $-.115^{*}$ & -.084 & $-.090^{\dagger}$ & -.063 \\
\hline Faculty $(1=$ social $\&$ art, $0=$ medical $\&$ natural $)$ & -.102 & $-.172^{\dagger}$ & -.089 & -.162 & -.071 & -.092 & -.033 \\
\hline Position $(1=$ above lecturer, $0=$ lower than lecturer $)$ & $-.149^{*}$ & .040 & -.063 & .015 & -.079 & .029 & -.010 \\
\hline Working hours per day & .040 & .005 & -.003 & .007 & .002 & .004 & -.007 \\
\hline Social support of workplace ${ }^{a}$ & $-.325^{* * *}$ & - & $-.200^{* * *}$ & - & $-.187^{* * *}$ & - & $-.181^{* * *}$ \\
\hline Interaction: Direct harassment $*$ Social support & & - & $-.403^{*}$ & - & $-.303^{*}$ & - & $-.218^{\dagger}$ \\
\hline Interaction: Indirect harassment ${ }^{*}$ Social support & & - & .035 & - & -.049 & - & -.047 \\
\hline $\mathrm{R}^{2}$ & & $.265^{* * *}$ & $.352^{* * *}$ & $.228^{* * *}$ & $.300^{* * *}$ & $.236^{* * *}$ & $.302^{* * *}$ \\
\hline $\mathrm{R}$ & & .515 & .593 & .477 & .548 & .486 & .549 \\
\hline
\end{tabular}

Model 1 adjusted for age, marital status, children, self-reported health status, self-reported household income, department, position, working hours per day.

Model 2 included social support and interaction.

aBased on a scale (Komaki and Tanaka, 1993) that measure to what extent a boss or a colleague in the workplace would provide supportive behaviors and communication.

$* * * p<.001 ; * * p<.01 ;{ }^{*} p<.05 ; \dagger p<.10$. 
Table 4. Effect of Three Types of Harassment on Burnout: Female.

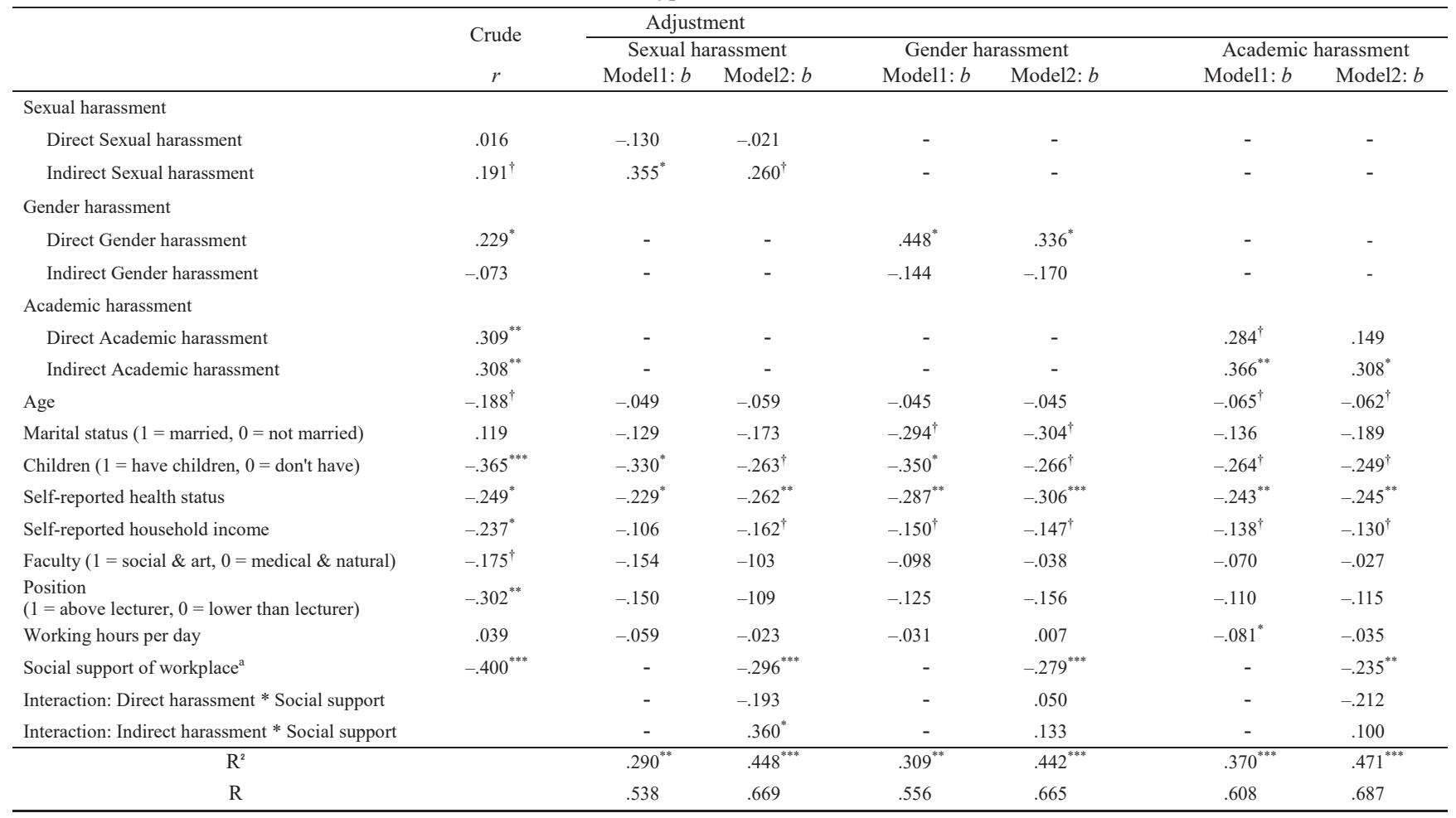

Model 1 adjusted for age, marital status, children, self-reported health status, self-reported household income, department, position, working hours per day.

Model 2 included social support and interaction.

aBased on a scale (Komaki and Tanaka, 1993) that measure to what extent a boss or a colleague in the workplace would provide supportive behaviors and communication.

$* * * p<.001 ; * * p<.01 ;{ }^{*} p<.05 ;{ }^{\dagger} p<.10$.

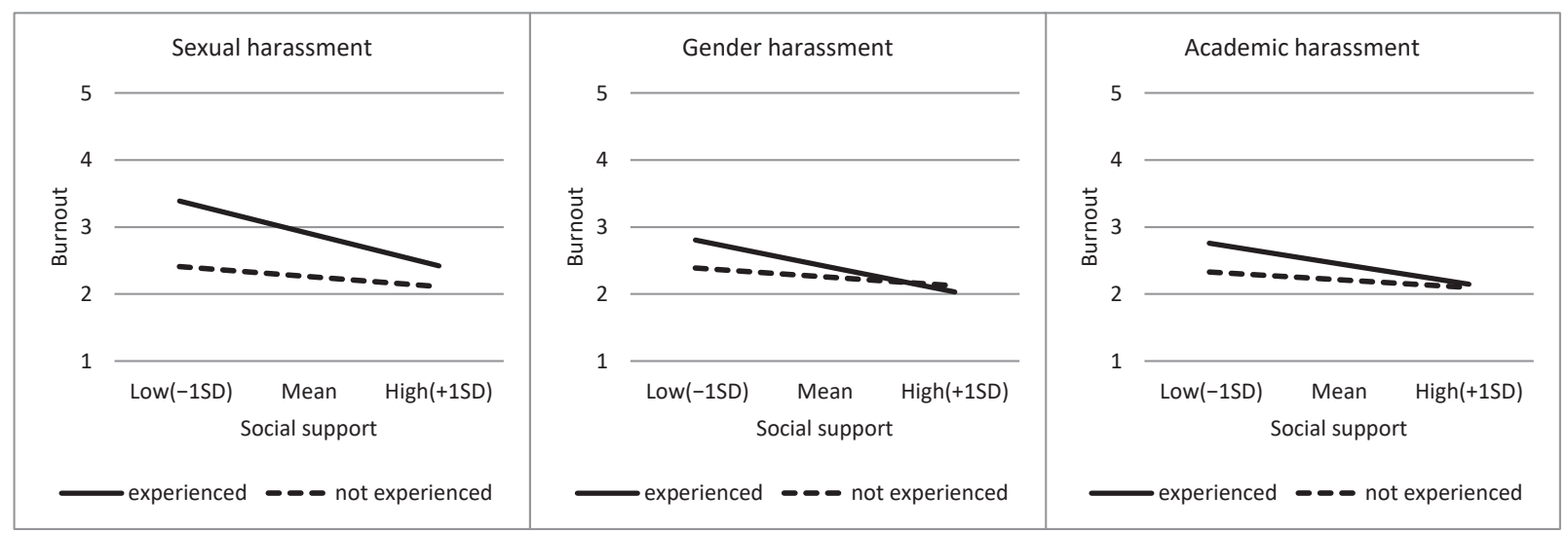

Fig. 1. Interaction of Social support and three types of Direct Harassment in males

Simple slope analysis for the association between direct experience of harassment and burnout tested for low ( -1 SD below the mean) and high ( +1 SD above the mean) levels of social support.

In contrast, similar modeling among females revealed considerably different results (Table 4). Among three types of harassment, the only direct experience that was significantly associated with greater burnout was direct experience of gender harassment $(b=.448, p<.05)$. However, indirect experiences of sexual harassment and academic harassment were positively associated with greater burnout among females (sexual harassment: $b=.355, p<.05$, aca- demic harassment: $b=.366, p<.01$ ), even though direct experiences were not. There were significant interactions between social support and the indirect experience of sexual harassment among females $(b=.360, p<.05)$. In Fig. 2 , simple slope analysis for this interaction showed high social support reduced burnout among females who did not experience indirect sexual harassment $(b=-.388, p<.001)$ but social support did not decrease burnout among females who 


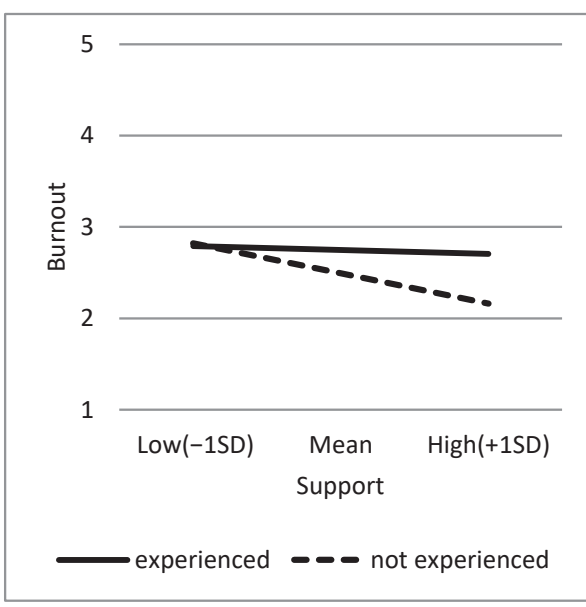

Fig. 2. Interaction of Social support and Indirect Sexual harassment in females.

Simple slope analysis for the association between indirect experience of sexual harassment and burnout tested for low ( -1 SD below the mean) and high (+1 SD above the mean) levels of social support.

had an indirect experience of sexual harassment $(b=-.050$, n.s.).

\section{Discussion}

This study of Japanese university faculty demonstrated that (1) females were more likely to report experiencing harassment both directly and indirectly as compared to their male counterparts; (2) males were more likely to have higher burnout scores if they experienced direct harassment (any of the three types), and this effect was ameliorated by social support; (3) females were more likely to have higher burnout scores if they perceived indirect experiences of sexual or academic harassment, and this relationship wasn't ameliorated by social support.

The finding that females serving on a private university faculty were more likely to have experienced harassment than their male colleagues may seem unsurprising. Because the university where this study was conducted actively promotes gender equity in the workplace, we felt that a survey about arguably sensitive issues such as sexual harassment would reveal more accurate responses. Indeed, the prevalence of the harassment experienced in our study is quite small compared to the previous study using the same scale conducted in companies in 1998 (Sano and Munekata 1999). We believe our study findings merit further attention, however, as our findings may therefore underrepresent the magnitude of the problem of harassment. We believe it is a topic worth studying in other Japanese workplaces, the majority of which also face challenges of gender inequity.

Additionally, our study yields several important insights for males. It suggests that some males were also victims of direct sexual, gender, and academic harassment, and such experiences increase the risk of burnout. In addition, younger males (who are most likely earlier in their careers) were more likely to experience all types of harassment compared to older males in academia. In addition, burnout associated with harassment was weakened by social support. Social support, therefore, may have a buffering effect on negative mental health outcomes (House et al. 1988). Indeed, social support at the university where this study was conducted included a consultation service, mentorship, and seminars/curricula/workshops on strategies to combat gender inequalities and harassment. These social support programs, while primarily meant to assist females, may contribute meaningfully to a supportive atmosphere for both males and females in the academic workplace.

Unlike males, in females, an indirect experience of sexual and academic harassment, as well as a direct experience of gender harassment, increased the risk of burnout, after adjusting for age, marital status, children, self-reported health status, self-reported household income, department, position, and daily working hours. Because gender harassment experiences in females may sometimes encourage a female to overwork in an attempt to demonstrate that her ability is not inferior to her male counterparts, such behavior may increase burn out (Parker and Griffin 2002). Our observation of a strong impact of indirectly experienced, "seen and heard" experiences of harassment might further suggest that females are sensitive to a more general culture of gender bias. This is consistent with results of a previous study which found that females who were aware of colleagues' sexual harassment experiences rated the environment as less supportive than those who had directly experienced harassment (Bond 1990). Furthermore, the likelihood of seeking assistance among indirect victims of harassment may be smaller compared to direct victims of harassment, which may ironically put females who have only indirectly experienced harassment at a higher risk of becoming psychologically isolated from the community, potentially resulting in early retirement or increased tendency to shift to part-time labor (Nomura and Gohchi 2012).

There were several limitations in the current study. First, the burnout scales used in our study were originally divided into three dimensions of emotional exhaustion, depersonalization, and personal accomplishment (Maslach and Jackson 1981; Tao and Kubo 1992). Although not reported here (as we utilized total burnout scores), additional sub-analyses utilizing the three dimensions were consistent with the present study. In males, direct experiences of sexual, gender, and academic harassment increased the risk of any types of burnout dimensions respectively; in females, direct and indirect experiences of sexual and academic harassment increased the risk of emotional exhaustion while direct experiences of gender harassment increased the risk of depersonalization. Second, the response rate for our survey was low at $27.9 \%$, which may indicate bias. Those who were more attuned to problems of harassment and gender may have opted in, and those who were very burned out may have opted out (Keeton et al. 2007). Third, our study population is derived from the fac- 
ulty of one private university with a relatively small sample size. Nevertheless, the surveyed university is representative in that nearly $80 \%$ of Japanese universities are private and feature a wide range of departments and coeducational schooling. Lastly, we did not measure the severity of harassment. Because some types of harassment, such as sexual harassment, have a wide range of features (Till 1980), females might have experienced more severe forms of psychologically damaging harassment compared to males, and may tend to underreport such harassment (Jagsi 2018). In such instances, social support might not be as useful as more intense support in the form of medical treatment or formal psychological intervention. Fear of retaliation from reporting may also explain why females were more likely to report indirect harassment rather than direct harassment across all three types of harassment.

In conclusion, we demonstrated that both males and females experience harassment, and that not only direct but also indirect effects of harassment can increase burnout among university faculty members. Interventions targeted to ameliorate harassment and to promote the psychological wellbeing of all faculty members may promote retention and advancement of both males and females in Japanese academia. Such efforts are critical to sustaining and growing the academic workforce in a country faced with declining scientific output on the global stage.

\section{References}

Andersen, G.R., Aasland, O.G., Fridner, A. \& Lövseth, L.T. (2010) Harassment among university hospital physicians in four European cities. Results from a cross-sectional study in Norway, Sweden, Iceland and Italy (the HOUPE study). Work, 37, 99-110.

Astrauskaite, M., Perminas, A.P. \& Kern, R.M. (2010) Sickness, colleagues' harassment in teacher's work and emotional exhaustion. Medicina (Kaunas), 46, 628-634.

Barrera, M., Sandler, I.N. \& Ramsay, T.B. (1981) Preliminary development of a scale of social support: studies on college students. Am. J. Community Psychol., 9, 435-446.

Bond, M. (1990) Division 27 sexual harassment survey: definitions, impact and environmental context. In Academic and Workplace Sexual Harassment, edited by Paludi, M. \& Barickman, R.B. SUNY Press, Albany, NY, pp.189-197.

Cohen, S., Mermelstein, R., Kamarck, T. \& Hoberman, H. (1985) Measuring the functional components of social support. In Social Support: Theory, Research, and Application, edited by Sarason, I.G. \& Sarason, B.R., Springer, Dordrecht, Netherlands.

Fitzgerald, L.F., Drasgow, F., Hulin, C.L., Gelfans, M.J. \& Magley, V.J. (1997) Antecedents and consequences of sexual harassment in organizations: a test of an integrated model. J. Appl. Psychol., 82, 578-589.

Fitzgerald, L.F., Gelfand, M.J. \& Drasgow, F. (1995) Measuring sexual harassment: theoretical and psychometric advances. Basic Appl. Soc. Psych., 17, 425-445.

Fuyuno, I. (2012) Numbers of young scientists declining in Japan, Nature News 2012

http://www.nature.com/news/numbers-of-young-scientistsdeclining-in-japan-1.10254

[Accessed: February 5, 2018].

Fuyuno, I. (2017) What price will science pay for austerity?
Nature, 543, S10-S15.

Gender Equality Bureau Cabinet Office, Government of Japan (2014) Annual Report on the Gender Equality: 2014.

http://www.gender.go.jp/about_danjo/whitepaper/h26/zentai/ index.html

[Accessed: March 27, 2018].

Glomb, T.M., Richman, W.L., Hulin, C.L. \& Drasgow, F. (1997) Ambient sexual harassment: an integrated model of antecedents and consequences. Organ. Behav. Hum. Decis. Process, 71, 309-328.

House, J.S., Umberson, D. \& Landis, K.R. (1988) Structures and processes of social support. Annu. Rev. Sociol., 14, 293-318.

Jagsi, R. (2018) Sexual harassment in medicine - \#MeToo. $N$. Engl. J. Med., 18, 209-211.

Kato, M., Chayama, H. \& Hoshikoshi, A. (2012) Analysis on ratio of women in science in Japan. http://hdl.handle.net/11035/1143 [Accessed: March 27, 2018].

Keeton, K., Fenner, D.E., Johnson, T.R.B. \& Hayward, R.A. (2007) Predictors of physician career satisfaction, work-life balance, and burnout. Obstet. Gynecol., 109, 949-955.

Komaki, K. \& Tanaka, K. (1993) The effect of the social support in a workplace. Kwansei Gakuin University school of sociology bulletin, 67, 57-67.

Lapierre, L.M., Spector, P.E. \& Leck, J.D. (2005) Sexual versus nonsexual workplace aggression and victim's overall job satisfaction: a meta-analysis. J. Occup. Health Psychol., 10, 155-169.

Maslach, C. \& Jackson, S.E. (1981) The measurement of experoenced burnout. Journal of occupational behaviour, 2, 99-113.

Ministry of Health, Labor and Welfare (2017) Monthly Labor Survey.

http://www.mhlw.go.jp/toukei/itiran/roudou/monthly/29/29r/ 29r.html

[Accessed : March 27, 2018].

Nomura, K. \& Gohchi, K. (2012) Impact of gender-based career obstacles on the working status of women physicians in Japan. Soc. Sci. Med., 75, 1612-1616.

Ogoshi, K. (2009) Current status and problems of harassment in universities in Japan. Acta Crim. Japon, 75, 165-168.

Ogoshi, K. \& Akamatsu, M. (2005) Academic harassment : questionnaire studies at universities in 2012. University Evaluation and Today, 1, 165-182.

Parker, S.K. \& Griffin, M.A. (2002) What is so bad about a little name-calling? Negative consequences of gender harassment for overperformance demands and distress. J. Occup. Health Psychol., 7, 195-210.

Raver, J.L. \& Gelfand, M.J. (2005) Beyond the individual victim: linking sexual harassment, team processes, and team performance. Acad. Manag. J., 48, 387-400.

Sano, S. \& Munekata, H. (1999) A survey of sexual harassment in the workplace: women's perceptions of sexual harassment. Japanese Journal of Administrative Science, 13, 99-111.

Sarason, I.G., Levine, H.M., Basham, R.B. \& Sarason, B.R. (1983) Assessing social support: the social support questionnaire. $J$. Pers. Soc. Psychol., 44, 127-139.

Tao, M. (1989) Burnout: a study of organizational stress among human service employees. Japanese Journal of Social Psychology, 4, 91-97.

Tao, M. \& Kubo, M. (1992) The measurement of burnout. Japanese Psychological Review, 35, 361-376.

Till, F.J. (1980) Sexual Harassment: A Report on the Sexual Harassment of Students, National Advisory Council on Women's Educational Programs, Washington, DC.

Vartia, M.A. (2001) Consequences of workplace bullying with respect to the well-being of its targets and observers of bullying. Scand. J. Work Environ. Health, 27, 63-69. 


\section{Appendix}

\section{Measures of harassment}

Have you ever directly experienced or seen-and-heard others experiencing the following in the university setting or associated workplace setting, such as research seminars or work-related social gatherings?

\section{Sexual harassment items}

1. Being asked, "Are you frustrated with lack of sexual activity?" or "Are you having your period ?"

2. Being asked, "Do you like sex?" or "Do you have sex too much?"

3. Being forced to serve sake by the offender.

4. Being forced to dance or sing with the drunken offender.

5. Being forced to hear dirty talk.

6. Being asked about your sex experience.

7. Being shown pornographic pictures or magazines.

8. Being physically touched around the breast, hip, or knee.

9. Being forced to go to a dinner not related to work.

10. Receiving pornographic letters or phone calls.

11. Being solicited for a sexual relationship in the workplace or with someone with whom you have a professional relationship.

\section{Gender harassment items}

1. Being told that you are effeminate if a man or masculine if a woman?

2. Being told that this job is not suitable to your gender?

3. Men being called by family name but women being called by first name.

4. Being called "my girl" rather than by real name.

5. Frequently having appearance mentioned, like clothes, hairstyle, and make-up.

6. Being told about body shape and appearance, for example, "Your breasts are big," or "Your hair is sparse."
7. Being told, "Your husband (your wife) will run away from you," or "You can never marry."

8. Being told, "I like young women / men," or "obasan (old woman) / ojisan (old man)."

9. Being asked, "Have you not married yet?" or "Why don't you marry?"

Academic harassment items

1. Being banned from attending a seminar or conference.

2. Having research budget cut or decreased.

3. Being insulted that "your research is dull."

4. Having someone limit your access to use of research equipment.

5. Removal of personal belongings while the person is absent from the scene.

6. Excluded certain people from teaching responsibilities of lectures and laboratories.

7. Incurred more teaching responsibilities to certain people.

8. Complaints about the way of teaching by boss or colleagues.

9. Rumors being spread with vicious intent.

10. Being forced to change research topics.

11. Having laboratory or research space taken away.

12. Having one's name replaced or moved from the first author position of scientific papers.

13. Being removed from coauthor lists of scientific papers.

14. Having had a research result stolen by a superior.

15. Being forced to be involved in technical work but being excluded from scientific writing and publication for credit.

16. Being abused verbally by a superior.

17. Feeling difficulty to apply for vacation leave.

18. Being told, "You are considered to be off duty if you are not available when I look for you at workplace."

19. Being told to resign or forced to apply to a position that you aren't interested in. 